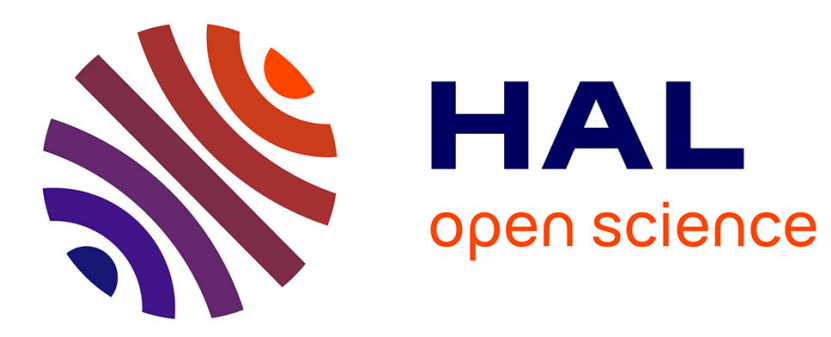

\title{
Modelling, Printing and Validation of Dental Dry Models for Implantology Skills Training
}

Ramses Albuquerque, Giovanny Arbelaez, Fabio Cruz, Mauricio Camargo, David Joseph, Nguyen Tran

\section{- To cite this version:}

Ramses Albuquerque, Giovanny Arbelaez, Fabio Cruz, Mauricio Camargo, David Joseph, et al.. Modelling, Printing and Validation of Dental Dry Models for Implantology Skills Training. 2018 IEEE International Conference on Engineering, Technology and Innovation (ICE/ITMC), Jun 2018, Stuttgart, France. 10.1109/ICE.2018.8436302 . hal-01858370

\section{HAL Id: hal-01858370 \\ https://hal.univ-lorraine.fr/hal-01858370}

Submitted on 29 Mar 2019

HAL is a multi-disciplinary open access archive for the deposit and dissemination of scientific research documents, whether they are published or not. The documents may come from teaching and research institutions in France or abroad, or from public or private research centers.
L'archive ouverte pluridisciplinaire HAL, est destinée au dépôt et à la diffusion de documents scientifiques de niveau recherche, publiés ou non, émanant des établissements d'enseignement et de recherche français ou étrangers, des laboratoires publics ou privés. 


\section{Modelling, printing and validation of dental dry models for implantology skills training}

\author{
Ramsés Albuquerque; Giovanny Arbelaez; Fabio Cruz; Mauricio Camargo \\ Équipe de Recherche sur les Processus Innovatifs, ERPI \\ Université de Lorraine \\ F-54000 Nancy, France \\ giovanny.arbelaez-garces@univ-lorraine.fr
}

\author{
David Joseph; Nguyen Tran \\ UMR-S1116 and Faculty of Dentistry \\ Université de Lorraine \\ F-54000 Nancy, France
}

\begin{abstract}
The acquisition of procedural technical skills is essential to become a surgeon. Traditional medical training required to practice procedures in cadavers and animals. New technologies such as virtual reality and additive manufacturing can help surgeons to learn and improve their skills through physical models of the human organ to be intervened. However, shape representation is not enough to have a realistic training experience. Training models need to biomimicry the real organs in other types of properties such as texture, density, mechanical behaviour among other properties. Therefore, different 3Dprocesses materials, textures and densities need to be explored and tested. The goal of this work was the development and validation of a dental dry model system using additive manufacturing. The mechanical profile of the printed models by capturing the force applied by a dental micro motor attached to a CNC machine during a standardized drilling test is measured. This research work was done in collaboration with the Nancy School of Surgery to help develop a new system to guide the training process for dentistry surgical procedures.
\end{abstract}

Index Terms-Dry Model, Additive Manufacturing, 3D Printing, Surgical training

\section{INTRODUCTION}

Simulation-based training (SBT) plays a major role in the educational process for acquiring the complex technical skills for surgical procedures in the medical field. The traditional practice of direct training on patients has been replaced due to the concern of patients' safety and prolonged operating times [1]. The many available models (animals, human cadavers) and new technologies of robotics and virtual reality $[2,3]$ allow skills acquisition and practice in a semi-realistic context. The use of simulation and models increases students' level of skill acquisition. New technologies lead to the development of simulation pedagogy for the training of interns in surgery in order to improve learning and cognition for the student/novice learner [1]. On the other hand, since late 1980s, additive manufacturing (AM) have emerged as an innovative set of technologies to produce objects layer-by-layer with higher flexibility, greater material efficiency with respect to traditional manufacturing, impacting in the product development time, cost reduction, human interaction and consequently the product development cycle [4-6]. There have been a number of significant changes that has led to improvements in accuracy, better mechanical properties, a broader range of applications

\footnotetext{
This is an author's version.
}

and reductions in costs of machines and the parts made by them. The driving force from academia/industry has been changing AM techniques from rapid prototype fabrication to rapid tooling and direct digital manufacturing [7,8]. Due to these developments in AM, biomedical and dentistry domains are a great opportunity to explore. In these fields, the main benefit is primarily in the capability to include patient-specific data from medical sources so that customized solutions to medical problems can be found.

In this research within the framework of a dentistry surgical training program, functional training 3D printed models were manufactured and tested in order to emulate the drilling process of a human jaw bone using a dental micro motor device. A design of experiments (DoE) approach was used in order to validate and compare the results between the real human jaw and the printed models. The remainder of this paper is structured as follows. Section II presents an insight from literature about the methods used in surgical simulationbased training. Then, in section III the methodology used in this research is presented. Section IV presents the application case. Section V shows a descriptive analysis of the results and the validation of the printed models. Finally, conclusions and different research perspectives are presented in section VI.

\section{BACKGROUND ON SIMULATION-BASED TRAINING (SBT) AND ADDITIVE MANUFACTURING}

\section{A. Simulation-based training (SBT)}

Table I presents an overview of recent works about surgical simulation training. We differentiate two types of goals of the training process, (1) assistance and (2) learning the surgical gestures. For doing that, we mapped if the support used is a real or a virtual model.

Table I: A simplified review on surgical simulators

\begin{tabular}{c|c|c|c|c}
\hline & \multicolumn{2}{|c|}{ Type of model } & \multicolumn{2}{c}{ Surgical gesture } \\
Author & Real & Virtual & Assistance & Learning \\
\hline$[9]$ & & $\mathbf{X}$ & & $\mathbf{X}$ \\
{$[10]$} & $\mathbf{X}$ & & & $\mathbf{X}$ \\
{$[11]$} & & $\mathbf{X}$ & & $\mathbf{X}$ \\
{$[12]$} & $\mathbf{X}$ & & & $\mathbf{X}$ \\
{$[13]$} & $\mathbf{X}$ & & $\mathbf{X}$ & \\
\hline
\end{tabular}


Analysing the table I, it is possible to observe that surgical simulation converges towards the use of real models for training. However, in a more detailed analysis of existing physical training models, authors found that they are limited in form and lack realism in mechanical characteristics (density, texture, etc.). It was due to this analysis that we were interested in a particular training simulator type the "Dry Model".

1) Dry Model:

The Dry Model is a type of surgical simulator that is inexpensive and easy to prepare and use. They were designed to replace corpses and animals during surgical simulation. Dry Models require much less preparation and cleaning time, are less expensive, have replaceable parts and make it easier to practice unsupervised training compared to cadaveric specimens [1]. One type of dry-model used in dental implantology are resin models. The sensation in piercing the resin of the jaw is that it is fully filled, so this type of prosthesis will not provide the strength of the depth sensation that is in the actual bones.

2) Properties of Cortical Bodies:

Knowledge of the mechanical properties of human bone is important to understand the mechanism of bone fractures, as well as for the design of orthopaedic devices and operations. The mechanical properties of cortical bone can be determined using a variety of methods, each test reveals different details on mechanical behaviour, and several types of tests are needed for a complete description of the mechanical response of bone tissue [10].

A human bone has anisotropic mechanical properties. The bone is not hard like glass or metal and differently from these materials, it does not respond linearly because it does not yield and deform uniformly during the loading phase [14]. Bone is a hierarchical, heterogeneous and anisotropic composite [15]. This anisotropic material indicates that the behaviour of the bone will change depending on the direction the load is applied [14].

The mechanics of viscoelastic and anisotropic material are not well understood, and bone materials properties vary considerably according to age, gender and health status [16].

3) Drilling Procedures:

Bone drilling is used in many surgical procedures, such as orthognathic surgery, dental implantation and spine surgery [16]. Safe and efficient drilling requires surgeon's dexterity and use of proper tools. With technological advancement, the instruments used in orthopaedics surgeries have been improved. However, new technologies are not enough for safe surgical procedures, there are several factors that if they are not properly controlled, can induce damage to bone tissue [14]. In the bone drilling process during a surgical procedure, a temperature increase due to high friction of the bone can damage the bone and the soft tissues. Overheating is generally recognized as a rise in temperature exceeding $47^{\circ} \mathrm{C}$, a critical limit above which drilling will cause osteonecrosis [17].

During surgical procedures where bone-machining operations are involved (drilling, sawing, etc.), mechanical and thermal loads can damage bone tissue and therefore working conditions should be selected to reduce or avoid this problem [18]. In bone drilling, a correct combination of parameters can reduce or even avoid the damage caused in these types of procedures. Several studies have been published on bone drilling, primarily analysing the effects of cutting conditions, such as speed of rotation and feed rate, on the temperatures and cutting forces achieved [18].

\section{B. Additive Manufacturing}

According to ISO/ASTM 52900, there are seven main types of AM technologies, namely [8, 19]: (1) binder jetting, (2) direct energy deposition, (3) material extrusion, (4) material jetting, (5) powder bed fusion, (6) sheet lamination, and (7) vat photo-polymerization. On the other hand, from a material perspective, another criteria used for classification is the initial state of the feedstock material (e.g. powder, sheet, wire, liquid) $[4,20]$. For each type of AM process, the feedstock must be formed into a state compatible with the process related. Figure 1 gives an overview of the different categories and principles of the AM technologies.

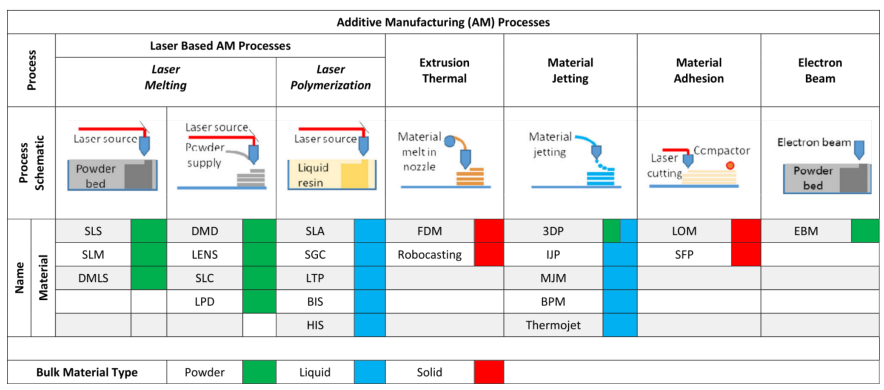

Figure 1: AM categories and principles [21].

The different processes are briefly explained as follows:

\section{- Laser-based processes:}

These processes use a laser source of medium to low power in order to melt, solidify or cure the material. The laser-based processes can be distinguished in two subcategories, depending on the phase change mechanism, namely laser melting and laser polymerization. In the laser melting processes, the material supplied state is in the form of fine powder. The material then cools down and solidifies to form the final part. On the other hand, laser polymerization process is characterized by the conversion of a liquid photosensitive monomer resin (usually highly cross-linked) into solid objects via photoinduced polymerization using a low-power laser source.

\section{- Extrusion processes:}

This process deposits a thread of molten material usually from a plastic filament, onto a substrate with the use of a movable head. The material is heated to a temperature slightly above its melting point within the head, then extruded through a nozzle to a substrate and cooled down until it solidifies and forms a layer and subsequently fabricating the final part geometry.

\section{- Material Jetting:}


The process principle is the use of thin nozzles in order to "spray", in a controlled manner, either molten material or more usually a binder (adhesive) in order to bind the powder in a solid object. The process operating principle is much like all the laser-melting processes, albeit no phase change occurs; instead, the binder holds the powder particles together.

\section{- Material Adhesion:}

This process combines the additive and the subtractive manufacturing techniques to build layer-by-layer the object. In this process, the principle consists in the overlaying of sheet materials that are supplied from a roll, and the contour of each layer is cut with a $\mathrm{CO}_{2}$ laser that is carefully modulated to penetrate a depth of exactly one layer thickness. Layers can be bonded together by pressure and heat application using a thermal adhesive coating. In consequence, the 3D parts are then fabricated by sequentially laminating and cutting $2 \mathrm{D}$ cross-sections [22, 23].

- Electron Beam: Electron beam processes focused the thermal energy used in order to fuse materials by melting as they are being deposited. An electron beam powered by a high voltage, typically $30-60 \mathrm{KV}$ is used as an energy source in order to melt or sinter the material.

There are four main application applications of AM in the medical domain [24]:

1) fabrication of biological and pre-surgical models

2) fabrication of scaffold for cell growth and tissue engineering

3) fabrication of human and living body prostheses and implants

4) design and fabrication of dental prostheses

In function of these four main objectives, each type of technology present advantages and disadvantages in terms of bio-compatibility, precision, and type of materials Dawood et al. [25]. In the context of training/teaching medical purposes, one of the main AM applications is the reproduction of anatomical prosected human cadaver and other anatomical specimens Mcmenamin et al. [26].

Concerning this research, the main interest is to adapt the additive manufacturing technology for training purposes in surgical dental implantology. The main goal is to obtain dry models in order to replicate the mechanical profile in the drilling process.

In the next section we present the methodology used in this research based in the considerations of the background explored.

\section{ReSEARCH Methodology}

Figure 2 displays the methodology used in this research. The methodology is composed of three main phases: Planning, Fabrication and Evaluation. The global goal in the deployment of the methodology is to evaluate the pertinence of the additive manufacturing technology in the educational training of the dental surgery.

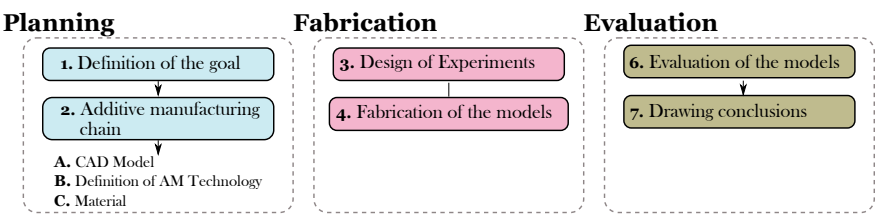

Figure 2: Methodology used in this research.

The main aim of planning stage is to define the scope of the implementation of additive manufacturing on the dental domain. In the scientific literature, there can be different levels to explore going from the biomimicry of the organic form to the replication of the functional elements. Therefore, in order to delimit the scope of the application of AM, the first element to define is the goal to explore with the introduction of AM. The second element to define is the technology associated that can respond to the goal attended. The AM chain there are different elements to be take into account. In the first place, it is necessary to consider the acquisition of a $3 \mathrm{D}$ digital model. In dentistry and surgery, one option is to have access to volumetric data in the form of computed tomography (CT) data, cone beam computed tomography (CBCT) data, and intra-oral or laboratory optical surface scan data [25]. The other option is to create objects from scratch using the different CAD software which is commonplace in industrial design, engineering, and manufacturing environments. Next, there are inherent advantages/disadvantages in the spectrum of AM technologies. These advantages/disadvantages are in terms of technical parameters (accuracy, speed production), economical and type of materials used. Moreover, the manufacturing parameters are close related to the type of technology used.

The second stage is fabrication. The main aim is to fabricate the printed samples according to the established protocol. The protocol is based on a design of experiments (DoE) approach. This protocol allows users to define elements such as the control factors to evaluate, the fixed factors to consider, and the sequence and quantity of samples to manufacture. One of the available approaches is the Taguchi method, which has been proven to be successful for improvement of product quality and process performance [27, 28]. The Taguchi method is distinguished by a significant reduction in the number of tests, while keeping good elements ro understand the influence of the parameters. The experimenter freely chooses the factors and interactions to be studied according to the model he proposes, in close accordance with his objectives.

The final stage is evaluation. The goal of this step is to evaluate the $3 \mathrm{D}$ printed elements in order to compare the performance between a real and a printed model. From these results, different conclusion can be drawn in order to better adjust the process.

\section{Case Study}

A case study is developed in the following sub-sections in order to illustrate the application of the presented methodology. 


\section{A. Planning}

1) Definition of the goal:

The goal of this research is to compare the mechanical profile in the drilling process of a human jaw bone and a functional 3D printed model using a dental micro motor experimental set-up.

2) Additive Manufacturing chain:

a) CAD Model:

A rectangle of dimensions $25 x 25 x 50 \mathrm{~mm}$ was used in the experimentation as illustrated in Figure 3.

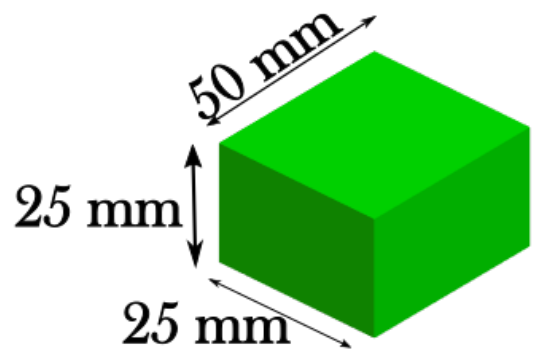

Figure 3: CAD model used in the experimentation.

b) Type of AM technology:

In the context of this research, an extrusion thermal process was selected for the experimentation. More precisely, A 3D printer based on the fused filament fabrication principle was chosen to test. Figure 4 display in more detail the operating principle and the parameters that needs to be considered in the manufacturing process.

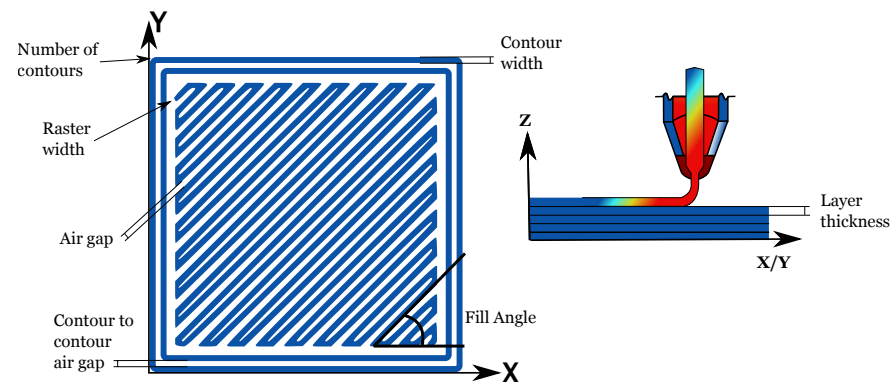

Figure 4: Parameters considered in the 3D printing process chain.

The parameters can be configured in order to obtain different samples based on a CAD model. The selection of parameters influences the dimensional accuracy, surface roughness and mechanical properties on the final parts. [29] presents in more detail the influence of manufacturing parameters in the quality of the printed part.

3) Design of Experiments:

Our goal with this experiment is to reproduce the mechanical resistance profile to the drilling process in dentistry. Therefore, the objective of this step is to establish the control factors to be evaluated, the fixed parameters to be considered and the sequence/quantity of samples to be made. In the literature, there have been several attempts $[5,24,30]$. Bose, Vahabzadeh, and Bandyopadhyay [30] presents a review focused on recent advances in bone tissue engineering scaffolds using additive manufacturing technology along with current challenges and future directions. The advances in therms of design shape, controlled chemistry, interconnection porosity and material for bone tissue engineering are presented. In order to simulate the real experiences of the drilling process in human bones and based on these literature, we choose three control factors:

- Fill density: This parameter represents the amount of material to fill inside the printed part. The density will be specified on the slicing software as a percentage $(0 \%$ for a hollow part) up to $100 \%$ (for a completely filled part).

- Perimeters: This specification corresponds to the number of solid layers around the printed part.

- Fill pattern: This parameter is the form of the filling inside the printed part. On the slicing process, different shapes of filling patterns are proposed (e.g. rectilinear, line, concentric, honeycomb, 3D honeycomb, Hilbert curve, Archimedean curve, spiral octagram). It forms the internal structure of the printed part.

Based on these three main control factors, three levels of each have been studied in this research. Table II presents the respective levels of each factor.

Table II: Control factors

\begin{tabular}{lc|ccc|}
\hline \multirow{2}{*}{ Control factors } & & \multicolumn{3}{|c|}{ Levels } \\
\cline { 3 - 5 } & ID & $\mathbf{1}$ & $\mathbf{2}$ & $\mathbf{3}$ \\
\hline Fill density & $\mathrm{A}$ & $25 \%$ & $50 \%$ & $75 \%$ \\
Number of perimeters & $\mathrm{B}$ & 1 & 3 & 5 \\
Infill Type & $\mathrm{C}$ & Rectilinear & Honeycomb & Hilbert Curve \\
\hline
\end{tabular}

Figure 5 displays graphically the selected control parameters.

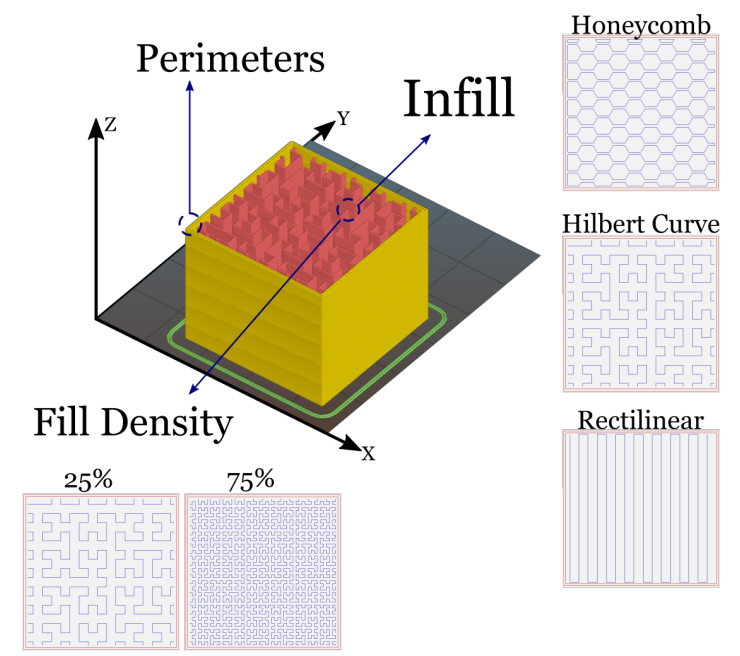

Figure 5: Control factor tested in the experimentation. 
In classical Design of Experiments (DOE), the study of three factors at three levels would require $27\left(3^{3}\right)$ experiments. Using Taguchi's approach, a reliable estimation of the effect of factors can be obtained by using an orthogonal array with fewer experiments. The appropriate orthogonal array for this experiment is $L_{9}\left(3^{4}\right)$. This array consists of nine rows for the experiment conditions of the control factors and four columns for assigning the factors or interactions. Columns 2, 3 and 4 are used for control factors A, B and C respectively. Table III shows the $L_{9}$ orthogonal array used in this investigation.

Table III: Taguchi's $\mathrm{L}_{9}\left(3^{4}\right)$ orthogonal array

\begin{tabular}{|c|c|c|c|c|c|c|}
\hline \multirow{2}{*}{$\begin{array}{l}\text { \# } \\
\text { Sample }\end{array}$} & \multicolumn{6}{|c|}{ Control factors } \\
\hline & $\mathbf{A}$ & $\mathbf{B}$ & $\mathbf{C}$ & Fill Density & \# Per. & Infill Type \\
\hline 1 & 1 & 1 & 1 & $25 \%$ & 1 & Rectilinear \\
\hline 2 & 1 & 2 & 2 & $25 \%$ & 3 & Honeycomb \\
\hline 3 & 1 & 3 & 3 & $25 \%$ & 5 & Hilbert Curve \\
\hline 4 & 2 & 1 & 3 & $50 \%$ & 1 & Honeycomb \\
\hline 5 & 2 & 2 & 1 & $50 \%$ & 3 & Hilbert Curve \\
\hline 6 & 2 & 3 & 2 & $50 \%$ & 5 & Rectilinear \\
\hline 7 & 3 & 1 & 2 & $75 \%$ & 1 & Hilbert Curve \\
\hline 8 & 3 & 2 & 3 & $75 \%$ & 3 & Rectilinear \\
\hline 9 & 3 & 3 & 1 & $75 \%$ & 5 & Honeycomb \\
\hline \multicolumn{7}{|c|}{ Additional printed part } \\
\hline 10 & & & & $100 \%$ & 2 & Rectilinear \\
\hline
\end{tabular}

An additional printed sample with $100 \%$ density (sample 10) was used fo comparison purposes regarding the other samples with a lower material density.

\section{B. Fabrication}

\section{1) Characterization of the machine:}

An open source 3D printer called "The FoldaRap" was selected for experimentation (figure 6). The FoldaRap machine is a representative 3D printer among all the machines developed by the RepRap community [31]. It is a Cartesian 3D printer where the extrusion system can be moved in the vertical plane $\mathrm{XZ}$ and the heated print bed can be moved in the horizontal direction - Y. The working capacity is $140 \times 140 \times 155 \mathrm{~mm} 3$. The extrusion system forces a filament with a diameter of 1.75 $\mathrm{mm}$ into a molten aluminium chamber, and then the filament is extruded through a $0.5 \mathrm{~mm}$ nozzle. The heated print bed improves the adhesion of the part with the printing bed. In terms of hardware and software, Slic3r software was used to convert STL files to Gcode, and Pronterface software was used as the system's host software.

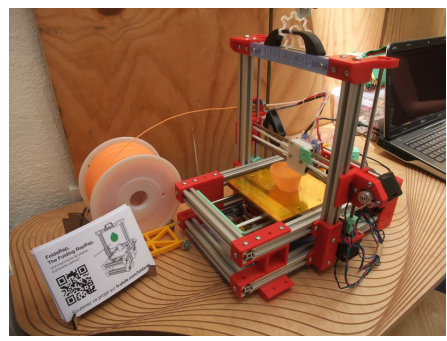

Figure 6: The Foldarap printer used in the experimentation.
Table IV presents the parameters that were fixed through the fabrication process.

Table IV: Fixed factors

\begin{tabular}{l|cc}
\hline Parameters & Value & Units \\
\hline Bed temperature & 60 & ${ }^{\circ} \mathrm{C}$ \\
Nozzle temperature & 190 & ${ }^{\circ} \mathrm{C}$ \\
\# of perimeters & 2 & \\
Top solid layers & 2 & \\
Bottom solid layers & 2 & $\%$ \\
Fill density & 30 & \\
Material & PLA & $\mathrm{mm} / \mathrm{s}$ \\
\# of repetitions & 2 & $\mathrm{~mm}$ \\
Travel speed & 200 & $\mathrm{~mm}$ \\
Nozzle diameter & 0.5 & \\
Filament Diameter & 1.75 & \\
Support & Non & \\
Slic3r (G-code) & & \\
\hline
\end{tabular}

\section{Measuring System}

To analyse the hardness measurements of the samples we pierced them with the help of a Makko M640 CNC machine. The milling motor on the machine was replaced with a Strausmann dental micro motor in order to obtain the same conditions of a clinical procedure and the minimal speed (2000 rpm). An Astra Tech Long Helical implantology drill, covered with titanium nitride and $2 \mathrm{~mm}$ in diameter was used. Finally, a two force-cells array was used to measure the applied force on the mandible while piercing. The force cells were connected to a Labview DAC for data acquisition. Figure 7 displays the schematic experimental set-up.

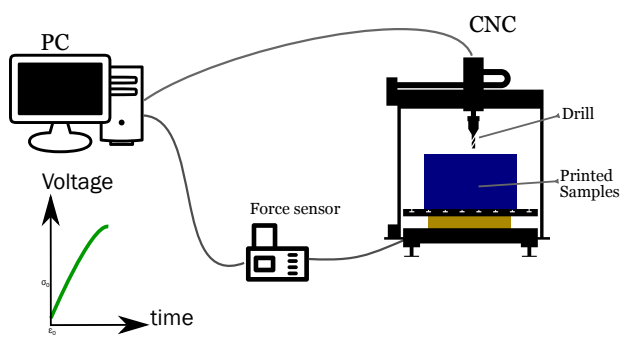

Figure 7: Schematic representation of the drilling experimental set-up.

\section{Evaluation}

\section{A. Mechanical profile of real human jaw}

A drilling test was made in order to have a reference signal about the mechanical behaviour of a real human jaw (cf. Fig. 8). Figure 9 shows the result of a drill test of the human jaw.

The $x$-axis displays the time in seconds and the $y$-axis displays the voltage value of the sensor. At the beginning of the tests, the graph rises to its maximum value, after this peak, the curve falls until finding the stability which shows a flat form. At the end of the test, the curve returns to the zero point. 


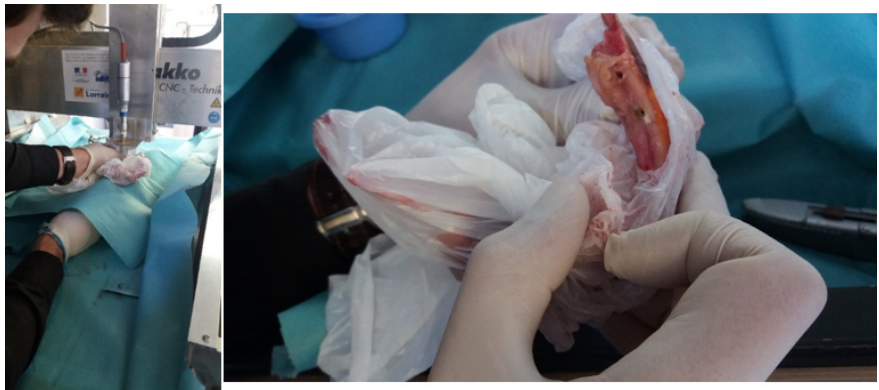

Figure 8: Human mandible piercing test.

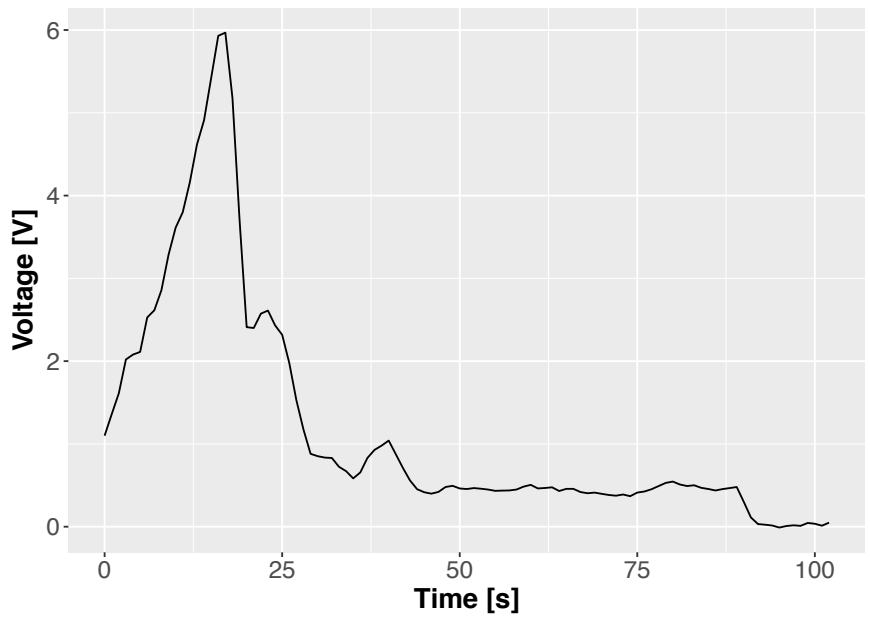

Figure 9: Profile of the mechanical resistance to be drilled of the Human Jaw's cortical bone.

This profile can serve as reference for comparison purposes. The parameters of the drilling process were set in order to respect certain aspects such as the maximal temperature achieved. This is very important because in a real context of surgery, the maximum temperature of $47^{\circ} \mathrm{C}$ cannot be exceeded.

\section{B. Mechanical profile of $3 D$ printed test}

A total of twenty printed samples were fabricated as illustrated in figure 10. The ten samples were made in polylactic acid (PLA) material and the ten others were made in acrylonitrile butadiene styrene (ABS). Each sample was submitted to a protocol of drilling established by the gcode used in the $\mathrm{CNC}$ machine for the drilling test. 500 measurements were taken per second in the drilling process in order to obtain a database with the voltage mean values at each second.

In the scientific literature, there are different measures of accuracy such as mean absolute error (MAE), mean squared error (MSE) and root mean squared error (RMSE). Table V displays the definition of each type of measurement. The main aim of these measurements is to compare the cumulative error between the printed samples and the human jaw profile. These values were calculated for each sample in order to identify the printed model with the most similar profile.

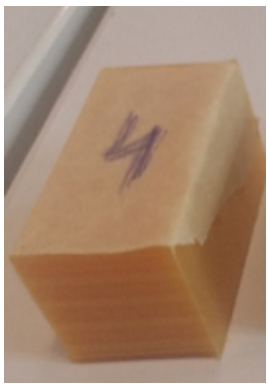

Figure 10: 3D printed cube model.

Table V: Measures of accuracy definitions

\begin{tabular}{l|lll}
\hline Measures of Accuracy & DAE & $=$ & $\frac{1}{n} \cdot \sum_{i=1}^{n}\left|r e f_{i}-x_{i}\right|$ \\
\hline Mean absolute error & MSE & $=$ & $\frac{1}{n} \cdot \sum_{i=1}^{n}\left(r e f_{i}-x_{i}\right)^{2}$ \\
\hline $\begin{array}{l}\text { Mean squared error } \\
\begin{array}{l}\text { Root mean squared } \\
\text { error }\end{array}\end{array}$ & RMSE & $=$ & $\sqrt{\frac{1}{n} \cdot \sum_{i=1}^{n}\left(r e f_{i}-x_{i}\right)^{2}}$ \\
\hline
\end{tabular}

Figure 11 displays the comparison of the different measures applied to our experimental case. It appears that the printed models (sample 8) represents the lower error value for the three types of accuracy measurements. Therefore, the factor A (fill density: 75\%), factor B (\# of perimeters : 3 ) and the factor $\mathrm{C}$ (fill type: rectilinear) give the profile that is the most similar regarding a human jaw bone. One interesting result is that the mechanical behaviour was similar for PLA as much as ABS. These exploratory results give us a first glimpse in order to better adjust the manufacturing parameters in the printing process.

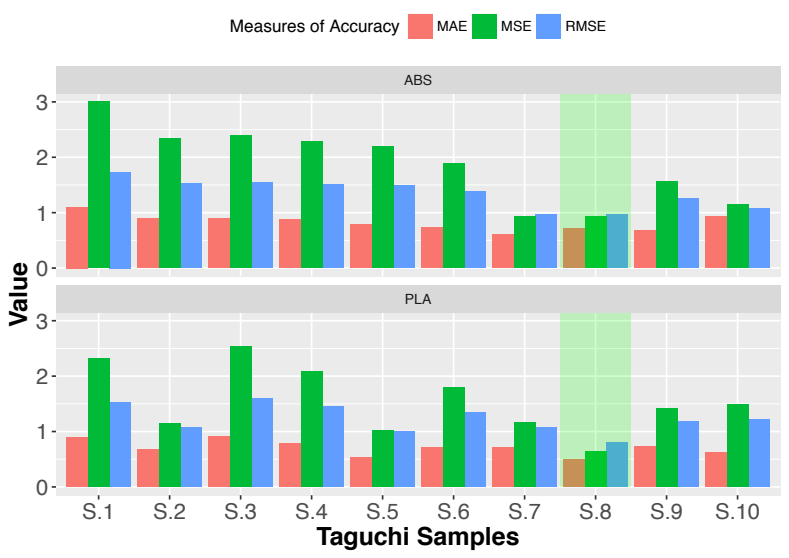

Figure 11: Error comparison between signals from human jaw bone and printed models.

Figure 12 displays the comparison of the mechanical profile of the human jaw bone and the printed models. 


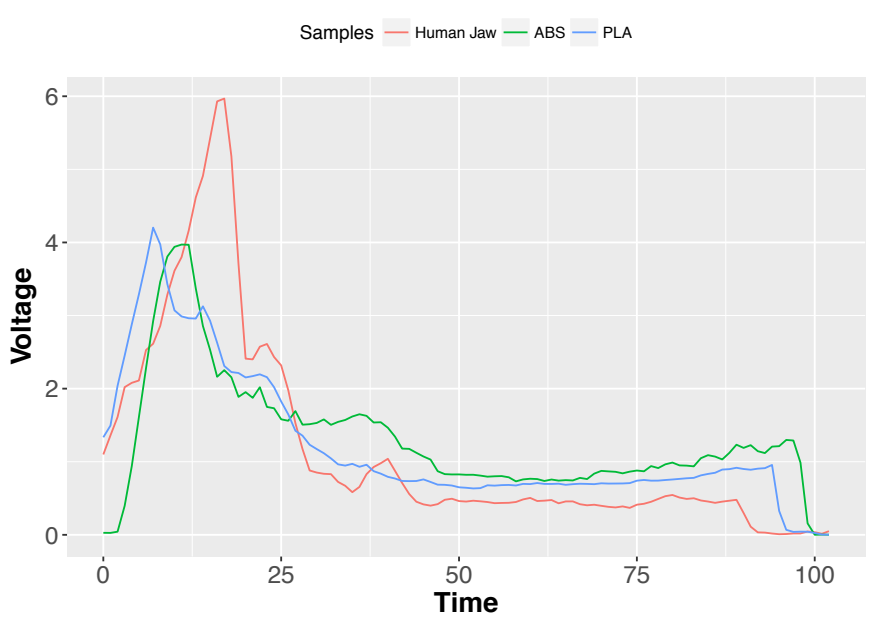

Figure 12: Mechanical drilling profile of human jaw bone and 3D printed models.

\section{Vi. Conclusion And Perspectives}

This research aimed to design a dry dental model to train and evaluate the learning of new surgeons. This study proposed to assess the mechanical force resistance to drilling of the models that were created by additive manufacturing. In the literature, dry models are proposed as pedagogical complements, but to our knowledge there are no propositions regarding a 3D printed dry model for dental implantology training. This study has demonstrated the ability to produce dry models for use in training dental surgery, it supposes several advantages: reduced associated cost compared to the maintenance of cadavers and the price of virtual simulators, the possibility of training outside training rooms. All the developed models presented visual characteristics close to the anatomical model. During this study, 10 PLA and 10 ABS square samples were printed. With open printers like the FoldaRap, it was possible to modify several control parameters, thus achieving different levels of hardness of the piece. Variations in the parameters of the PLA and ABS rectangular samples have made it possible to find parameters that allowed us to achieve more resistant samples. The drilling test also allowed us to find the drilling forces and to compare them to the mechanical characteristics of a human jaw. The dental dry model has great potential to be included in a useful way in surgical training, so this research could continue to explore other areas of surgery, not only in dental implantology. Two main directions for further research are being explored: for one part the possibility to recycle the models once used to produce new ones; and for the other part to perform usability test with surgeons in order to validate their perception of the proposed dry models performance and compare it to the proposed measurement.

\section{ACKNOWLEDGEMENTS}

Authors would like to thanks to CAPES (Coordenação de Aperfeiçoamento de Pessoal de Nível Superior), who provided a scholarship in the project BRAFITEC (Exchange Program between Brazil and France) for this research.

\section{REFERENCES}

[1] Robert D. Acton. "The Evolving Role of Simulation in Teaching Surgery in Undergraduate Medical Education". In: Surgical Clinics of North America 95.4 (2015), pp. 739-750.

[2] Cyril Perrenot et al. "The virtual reality simulator dVTrainer® is a valid assessment tool for robotic surgical skills”. In: Surgical Endoscopy 26.9 (2012), pp. 2587 2593.

[3] Giovanny Arbelaez-Garces et al. "Contribution to the objective assessment of technical skills for surgery students: An accelerometer based approach". In: International Journal of Industrial Ergonomics 64 (2018), pp. 79-88.

[4] Nannan Guo and Ming C. Leu. "Additive manufacturing: technology, applications and research needs". In: Frontiers of Mechanical Engineering 8.3 (2013), pp. 215-243.

[5] Mohammad Vaezi et al. "Multiple material additive manufacturing - Part 1: a review". In: Virtual and Physical Prototyping 8.1 (2013), pp. 19-50.

[6] Kaufui V. Wong and Aldo Hernandez. "A Review of Additive Manufacturing". In: ISRN Mechanical Engineering 2012 (2012), pp. 1-10.

[7] D T Pham and S S Dimov. "Rapid prototyping and rapid tooling - the key enablers for rapid manufacturing". In: Proceedings of the Institution of Mechanical Engineers, Part C: Journal of Mechanical Engineering Science 217.1 (2003), pp. 1-23.

[8] Ian Gibson, David W. Rosen, and Brent Stucker. Additive Manufacturing Technologies. Vol. 32. 2. Boston, MA: Springer US, 2010.

[9] L. M. Al-Saud et al. "Feedback and motor skill acquisition using a haptic dental simulator". In: European Journal of Dental Education 21.4 (2017), pp. 240-247.

[10] M. B. Putrik, Yu E. Lavrentyeva, and I. N. Antsygin. "Construction of Objects for Rapid Prototyping Manufacturing in Dentistry". In: Biomedical Engineering 50.2 (2016), pp. 134-137.

[11] Hideaki Kinoshita et al. "Development of a Drilling Simulator for Dental Implant Surgery." In: Journal of dental education 80.1 (2016), pp. 83-90.

[12] Gregory Lopez et al. "A cost-effective junior resident training and assessment simulator for orthopaedic surgical skills via fundamentals of orthopaedic surgery aaos exhibit selection: AAOS exhibit selection". In: Journal of Bone and Joint Surgery - American Volume 97.8 (2015), pp. 659-666.

[13] D. J. Thomas, M. A.B.Mohd Azmi, and Z. Tehrani. "3D additive manufacture of oral and maxillofacial surgical models for preoperative planning". In: International Journal of Advanced Manufacturing Technology 71.912 (2014), pp. 1643-1651. 
[14] Antonia Dalla Pria Bankoff. "Biomechanical Characteristics of the Bone". In: Human Musculoskeletal Biomechanics (2012), pp. 61-86. arXiv: 0803973233.

[15] Philippe K. Zysset, Jakob Schwiedrzik, and Uwe Wolfram. "European Society of Biomechanics S.M. Perren Award 2016: A statistical damage model for bone tissue based on distinct compressive and tensile cracks". In: Journal of Biomechanics 49.15 (2016), pp. 3616-3625.

[16] Yanping Lin et al. "A predictive bone drilling force model for haptic rendering with experimental validation using fresh cadaveric bone". In: International Journal of Computer Assisted Radiology and Surgery 12.1 (2017), pp. 91-98.

[17] Kadir Gok, Arif Gok, and Yasin Kisioglu. "Optimization of processing parameters of a developed new driller system for orthopedic surgery applications using Taguchi method". In: International Journal of Advanced Manufacturing Technology 76.5-8 (2014), pp. 14371448.

[18] Josu Soriano et al. "Study and improvement of surgical drill bit geometry for implant site preparation". In: International Journal of Advanced Manufacturing Technology 74.5-8 (2014), pp. 615-627.

[19] ASTM 52900:2015. "Standard Terminology for Additive Manufacturing - General Principles - Terminology". In: ASTM International i (2015), pp. 1-9. arXiv: arXiv:1011.1669v3.

[20] Yuwei Zhai, Diana a. Lados, and Jane L. LaGoy. "Additive Manufacturing: Making Imagination the Major Limitation". In: Jom 66.5 (2014), pp. 808-816.

[21] H Bikas, P Stavropoulos, and G Chryssolouris. "Additive manufacturing methods and modelling approaches: a critical review". In: The International Journal of Advanced Manufacturing Technology (2015), pp. 1-17.

[22] Michael Feygin and Brian Hsieh. "Laminated Object Manufacturing (LOM): A Simpler Process". In: Proceedings of Solid Freefonn Fabrication Symposium. Austin, TX 0 (1991), pp. 123-130.

[23] Bernhard Mueller and Detlef Kochan. "Laminated object manufacturing for rapid tooling and patternmaking in foundry industry". In: Computers in Industry 39.1 (1999), pp. 47-53.

[24] Wahyudin P. Syam, M. a. Mannan, and a. M. AlAhmari. "Rapid prototyping and rapid manufacturing in medicine and dentistry". In: Virtual and Physical Prototyping 6.2 (2011), pp. 79-109.

[25] A. Dawood et al. "3D printing in dentistry". In: British Dental Journal 219.11 (2015), pp. 521-529.

[26] Paul G. Mcmenamin et al. "The production of anatomical teaching resources using three-dimensional (3D) printing technology". In: Anatomical Sciences Education 7.6 (2014), pp. 479-486.

[27] Ali Azadeh et al. "Design and implementation of an integrated Taguchi method for continuous assessment and improvement of manufacturing systems". In: The
International Journal of Advanced Manufacturing Technology 59.9-12 (2011), pp. 1073-1089.

[28] William Y. Fowlkes and Clyde M. Creveling. Engineering Methods for Robust Product Design: Using Taguchi Methods in Technology and Product Development. Reading, MA: Addison Wesley Longman, Inc., 1995, p. 432.

[29] Brian N. Turner, Robert Strong, and Scott A. Gold. "A review of melt extrusion additive manufacturing processes: I. Process design and modeling”. In: Rapid Prototyping Journal 20.3 (2014), pp. 192-204.

[30] Susmita Bose, Sahar Vahabzadeh, and Amit Bandyopadhyay. "Bone tissue engineering using 3D printing". In: Materials Today 16.12 (2013), pp. 496-504.

[31] Fabio Alberto Cruz Sanchez et al. "Towards a standard experimental protocol for open source additive manufacturing". In: Virtual and Physical Prototyping 9.3 (2014), pp. 151-167. 